\title{
AVALIAÇÃo TÉCNICA DOS PREÇOS, PRODUÇÃO E ÁREA DE COLHEITA DA CULTURA DA SOJA NO ESTADO DE SÃO PAULO DE 2007 A 2017
}

\author{
BIZINOTTO, Danilo de Santi ${ }^{1}$ \\ MACIEL JÚNIOR, Vinícius Antônio ${ }^{2}$ \\ DUARTE, João Paulo Pereira ${ }^{1}$
}

RESUMO: O objetivo deste trabalho foi revelar um quadro representativo da produção da cultura da soja no país, considerando as variáveis de preço, produção e área de colheita. Tomando como base, dados dos últimos dez anos do Agrianual (2018), realizando uma análise da rentabilidade da soja, do ano de 2007 até o ano de 2017, outros fatores cruciais como custo, área plantada e produtividade, que nortearam a representação da cultura também foram analisados. As pesquisas se deram na biblioteca da FAFRAM através dos exemplares dispostos no local. Concluiu-se que a soja teve variação significativa e crescente durante o decorrer dos anos em todos os fatores analisados.

Palavras chave: Mercado agrícola. Glycine Max (L.) Merrill. Economia agrícola.

SUMMARY: The objective of this work was to reveal a representative picture of soybean crop production in the country, considering the variables of prince, production and harvesting. Based on data from the last ten years of the Agrianual (2018), analyzing soybean yield from 2007 to 2017, other crucial factors such as cost, planted area and productivity, which guided the representation of the crop were also analyzed. The research was done in the library of the FAFRAM through the copies arranged in the place. It was concluded that soybean had significant and increasing variation over the years in all the factors analyzed.

Keyword: Agricultural market. Glycine Max (L.) Merrill.Agricultura economy.

\section{INTRODUÇÃO}

A soja (Glycine Max (L.) Merrill) situa-se entre as mais importantes culturas na economia mundial. Seus grãos são comumente utilizados pela agroindústria na produção de óleo vegetal, bem como rações para alimentação animal, e pela indústria química e de alimentos. Nos últimos anos, vem crescendo também sua utilização como fonte de biocombustível alternativa (COSTA NETO; ROSSI, 2000). E desde então essa realidade se manteve constante devido à alta produção da cultura no Brasil.

A propagação da soja se deu inicialmente no continente europeu no ano de 1739, já nos Estados Unidos ocorreu em 1765. Em solo brasileiro os primeiros posteriormente no estado de São Paulo em 1891, chegando ao Rio Grande do Sul na década de X, por volta de 1914 (MUNDSTOCK; THOMAS, 2005).

A partir da década de 1960, surgiram as primeiras lavouras com intuito comercial, e que automaticamente se integraram rapidamente no sistema de rotação de verão com a cultura do milho, e também em sucessão com as culturas da cevada, trigo, aveia branca e aveia preta, sendo a mesma dessecada e usada como cobertura morta no período de inverno (MUNDSTOCK; THOMAS, 2005).

\footnotetext{
${ }^{1}$ Engenheiro Agrônomo pela FAFRAM

${ }^{2}$ Docente na FAFRAM E FAZU
} 
Desde então a cultura da soja vem se expandido no território nacional se mantendo como a principal do país. Segundo dados do portal da Empresa Brasileira de Pesquisa Agropecuária (EMBRAPA, 2017) o Brasil ocupa a segunda colocação no que se refere à produção no mundo, ficando

apenas atrás dos Estados Unidos da América - EUA.

Ainda de acordo com a empresa nacional, o país possui o maior potencial para expansão de área a ser cultivada. Para se ter uma ideia de acordo com a exigência do mercado, a produção nacional pode até duplicar, mostrando a potencialidade agrícola brasileira.

Segundo levantamento da Companhia Nacional de Abastecimento (CONAB, 2017) a produção estimada para o ano de 2018, deve ficar entre 223 a 227,5 milhões de toneladas, entorno de 6,2\% a 4,4\% abaixo do ano anterior. Contudo valores bastante representativos e que mantém o país como grande produtor da cultura. Em relação á área cultivada, a expectativa é de manutenção ou até mesmo aumento da área de cultivo de soja, cerca de 1,9\% de crescimento, ou seja em números a área de cultivo pode chegar a 62 milhões de hectares plantados.

$\mathrm{O}$ objetivo deste estudo foi $\mathrm{O}$ objetivo deste trabalho foi revelar um quadro representativo da produção da cultura da soja no país, considerando as variáveis de preço, produção e área de colheita.

A metodologia de estudo revela um quadro representativo da produção da cultura da soja no país. Tomando como base, dados dos últimos dez anos do Agrianual, realizando uma análise da rentabilidade da soja, do ano de 2007 até o ano de 2017, onde foi exposto o crescimento da cultura bem como sua importância no cenário agrícola brasileiro. Levando em conta fatores cruciais como custo, área plantada e produtividade, que nortearam a representação da cultura, uma vez que seu desempenho na última década reflete a economia do setor agrícola do país, bem como de seus respectivos produtores do grão.

\section{REVISÃO DE LITERATURA}

A comercialização trata-se de uma das etapas mais importantes inserida nas atividades desenvolvidas na agropecuária. É nessa fase que se decide um possível empreendimento, pela realização ou de lucro ou prejuízo. O próprio produtor de soja se preocupava com a comercialização do produto apenas após a colheita, isso se deve, principalmente, pela abundância em crédito de custeio. Durante certo tempo, o governo brasileiro assegurava aos mesmos os preços, atualmente, os créditos são mais escassos (BRAUN; TALAMINI, 2018).

Não bastasse essa realidade, o produtor enfrenta ainda outros fatores condicionantes na produção, como as mudanças climáticas, ocorrência de pragas e doenças, fatores que dificultam as estimativas de preço da soja. Nesse cenário os produtores utilizam outras formas de comercializar, como entregar o produto a terceiros, recebendo por vezes quantias menores as estabelecidas no mercado (BRAUN; TALAMINI, 2010).

E essa análise se faz importante, uma vez que o produto que mais influencia na expansão do agronegócio brasileiro é a soja. Como sugere Guanziroli (2006) que não considera apenas o grão cultivado, mas a necessidade de haver uma visão mais empresarial da atividade de todas as partes seja dos produtores, dos fornecedores de insumos de negociantes, bem como dos processadores da soja.

Um dos pontos que corroboram com esta realidade descrita por Guanziroli (2006) foi o processo histórico de implantação de programas de melhoramento da cultura no país, que possibilitaram a crescente produção da soja no território nacional, principalmente, em regiões de baixa latitudes, por meio de tecnologia voltada a criação de cultivares mais adaptadas à essas regiões, como exemplo, a introdução de genes que atrasam o florescimento da planta, mesmo em períodos e condições favoráveis ao fotoperíodo indutor (KIIHL; GARCIA, 1989). 
A partir da década de 90, a agricultura no geral se modernizou consideravelmente, o que de certa forma, diretamente, colaborou com a reestruturação da cultura da soja no decorrer da cadeia produtiva, devido às tecnologias novas disponíveis no mercado. Mostrando novamente a crescente aparição da

cultura no meio agropecuário, fazendo com que a mesma fosse essencial para setores primordiais no desenvolvimento de um país, como a geração de empregos, geração de rendas e também na abertura das divisas de exportação, fomentando parcerias internacionais que impulsionam a economia brasileira. Desmembrando todo esse mercador nacional forte, observando setores primários que fundamentam esse desenvolvimento.

No Brasil a maior parte colhida da soja, aproximadamente 30 milhões de toneladas, destina-se a indústria, que por sua vez transforma-a em óleos e farelos. Este está entre os primeiros mais utilizados na elaboração de rações animais.

De acordo com o Sindicato Nacional das Indústrias de Alimentação Animal - Sindirações o consumo interno de farelo de soja ultrapassaria as 12 milhões de toneladas, enquanto as exportações as 13 milhões de toneladas, conforme a Associação Brasileira das Indústrias de Óleos Vegetais (ABIOVE, 2011). O que foi confirmado na época e se manteve crescente nos últimos anos, devido à estabilidade da pecuária principalmente nas regiões do Centro-Oeste e Norte do país. Tanto que atualmente, a Abiove (2017) mostra uma elevação para 107,30 milhões de toneladas de safra de soja em 2017.

No Brasil, a comercialização da soja no mercado externo, é a principal ponte de lucratividade da cultura, comercializada como commodities. Consideram-se como commodities as mercadorias de primeira geração não manufaturadas, ou que sejam parcialmente manufaturadas, e que tenham uma alta exposição no mercado internacional. Já no mercado financeiro, uma commodity pode ser utilizada na sugestão de um tipo de produto, geralmente, este pode ser agrícola ou até mesmo mineral, mas que tenha participação considerável na economia internacional, pelo mesmo ser amplamente motivo de negociação entre grandes exportadores e importadores no mundo todo (IMEA, 2015).

E todos esses dados são confirmados, quando de acordo com a Conab (2018) a cultura da soja mantem-se na tendência de crescimento em área cultivada e na safra 2017/2018 a estimativa norteia para um crescimento de até $2,9 \%$ em comparação à safra anterior. Explicitando a segurança do produtor brasileiro e do mercado nesse commodity.

Por sua alta demanda, a soja é um produto com liquidez forte e conforme as boas expectativas da safra norte americana, os preços atualmente se encontram em considerados patamares remunerados pelos próprios produtores. Outro fator é o ambiente de eleições no ano de 2018, em paralelo a volatilidade da moeda americana, tem propiciado um suporte de preços no âmbito interno, o que reforçou a confiança do produtor paulista e brasileiro no investimento de áreas para as oleaginosas, a qual a soja está inserida (CONAB, 2018).

Em São Paulo, os primeiros levantamentos confirmaram um possível crescimento da área plantada com oleaginosas, principalmente, da soja, avançando em lavouras tradicionais como de milho em algumas regiões do estado, e em outros municípios sobre o cultivo de feijão. Tem como principal suporte a forte demanda do mercado chinês, que hoje é o principal parceiro do Brasil no setor. Além da alta do dólar, menor custo de produção, bem como, a maior liquidez na comercialização (CONAB, 2018).

Esse quadro favorece o crescimento da cultura no território paulista de tal forma a influenciar nos preços, área plantada e produtividade por hectare atrelado a tecnologia presente no estado mais rico da nação.

\section{MATERIAL E MÉTODO}


A pesquisa deste estudo foi fundamentada em sua totalidade no Agrianual, que é referência no Brasil com relação ao acesso direto das principais atualizações estatísticas do mercado agrícola, sendo fonte de informação completa e confiável que permite uma análise do mercado brasileiro. Tomou-se como

base o Agrianual de 2018 para a coleta dos dados da pesquisa. As consultas se deram na biblioteca da Faculdade Doutor Francisco Maeda, onde os exemplares estão dispostos para uso acadêmico.

As análises foram realizadas num período de 30 dias, percorrendo os meses de julho e agosto de 2018. Foram levados em conta para o levantamento, dez anos seguidos de dados estatísticos do Agrianual, sendo eles entre 2007 a 2017.

Os fatores que foram analisados e dispostos para discussões e comparações foram os seguintes: Preço, Produção (ton) e área colhida. O estado de São Paulo, $8^{\circ}$ maior produtor da cultura no país, foi escolhido para o levantamento, por se tratar de um dos estados mais rentáveis no que se refere à agricultura, além de possuir tecnologia avançada no cultivo da soja e ser o estado onde se situa o projeto de pesquisa.

Por meio dos dados alcançados, foram traçadas linhas que permitiram um maior entendimento das variações que ocorrem durante uma década. Foram utilizadas as ferramentas do pacote office para a apresentação dos resultados, como as tabelas criadas no Microsoft Word e gráficos criados no Microsoft Excel.

\section{RESULTADO E DISCUSSÃO}

Na tabela 1 são apresentados os resultados relativos aos preços, produção e área colhida, onde se pode observar que a variável preço teve uma variação porcentual de $118,25 \%$ nos últimos 10 anos, a produção variou $48,61 \%$ e a área colhida aumentou $39,54 \%$.

Tabela 1: Valores do Agrianual referentes a preço, produção e área colhida da cultura da soja entre os anos de 2007 a 2017.

\begin{tabular}{cccc}
\hline Soja & Preço & Produção & Área Colhida \\
\cline { 2 - 4 } Ano & $\mathrm{R} \$$ & Toneladas & Hectare \\
\hline $2007 / 2008$ & 32,16 & 1.446 .500 & 526.000 \\
$2008 / 2009$ & 43,38 & 1.306 .467 & 531.300 \\
$2009 / 2010$ & 43,37 & 1.586 .138 & 572.200 \\
$2010 / 2011$ & 37,28 & 1.708 .486 & 612.800 \\
$2011 / 2012$ & 43,20 & 1.597 .557 & 582.200 \\
$2012 / 2013$ & 59,80 & 2.051 .100 & 637.000 \\
$2013 / 2014$ & 57,96 & 1.688 .300 & 751.700 \\
$2014 / 2015$ & 59,22 & 2.366 .500 & 796.800 \\
$2015 / 2016$ & 62,54 & 2.843 .800 & 857.600 \\
$2016 / 2017$ & 70,19 & 2.815 .000 & 870.000 \\
\hline
\end{tabular}

Fonte: Agrianual (2018)

Os valores destacados na Tabela 1 são descritos nos Gráficos 1, 2 e 3 e permitem analisar os dados encontrados com maior propriedade, verificando-se a representação das variações encontradas, onde se percebe uma variação significativamente maior do preço com relação à produção e área colhida. 
Gráfico 1: Representação da variação de preço da soja em dez anos (2007-2017).

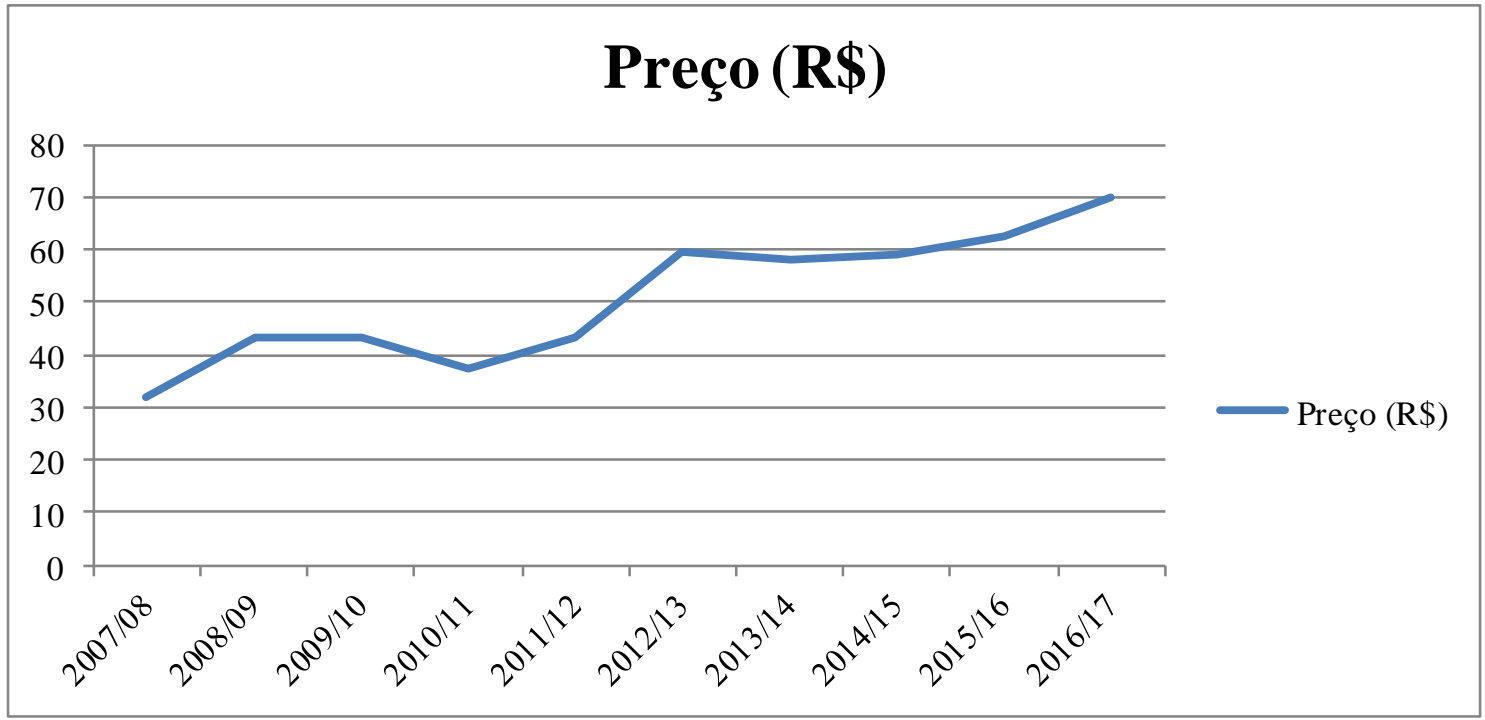

Fonte: Elaborado pelo autor (2018).

Gráfico 2: Representação da variação de produção da soja em dez anos (2007-2017).

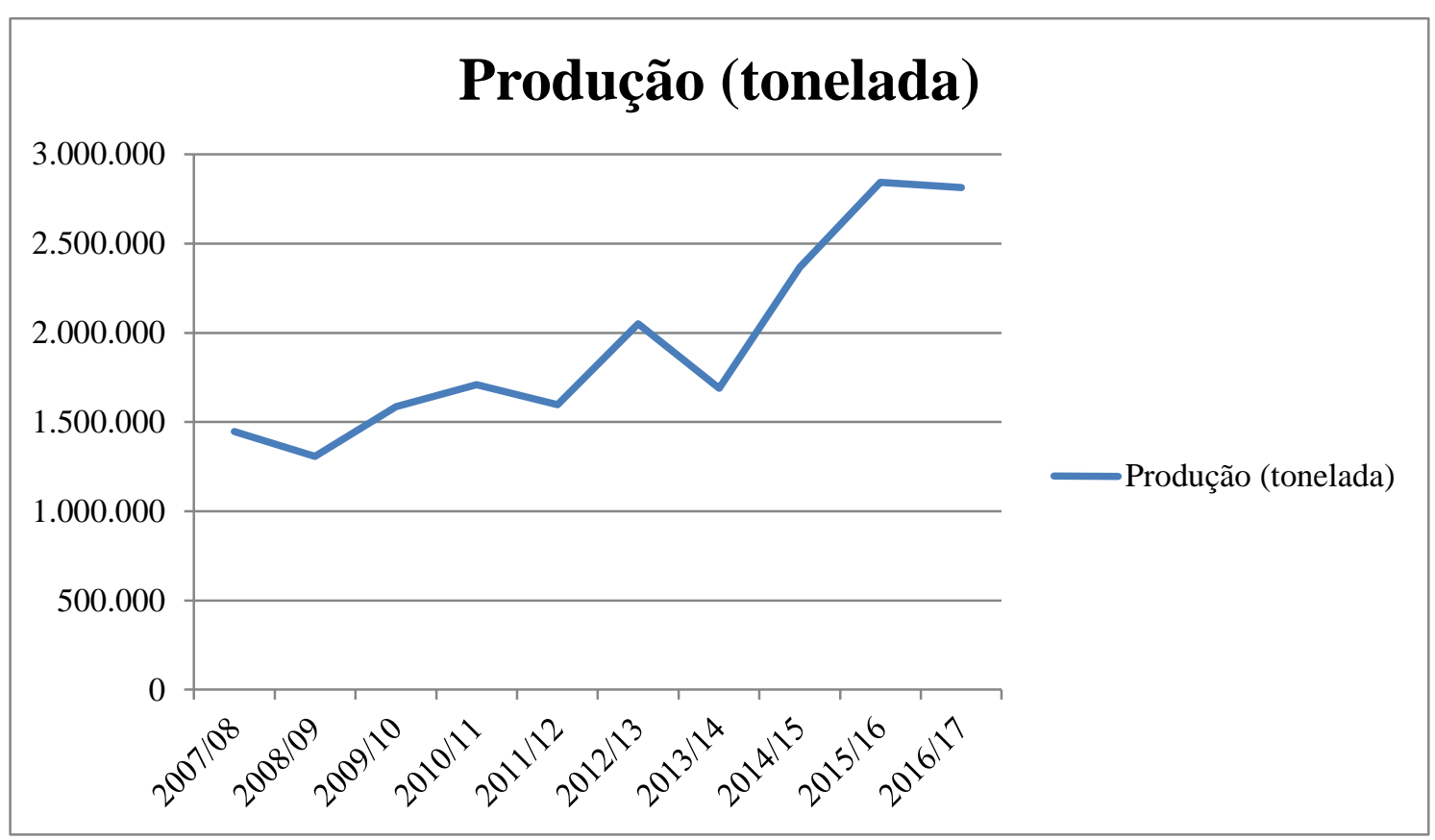

Fonte: Elaborado pelo autor (2018) 
Gráfico 3: Representação da variação de preço da soja em dez anos (2007-2017).

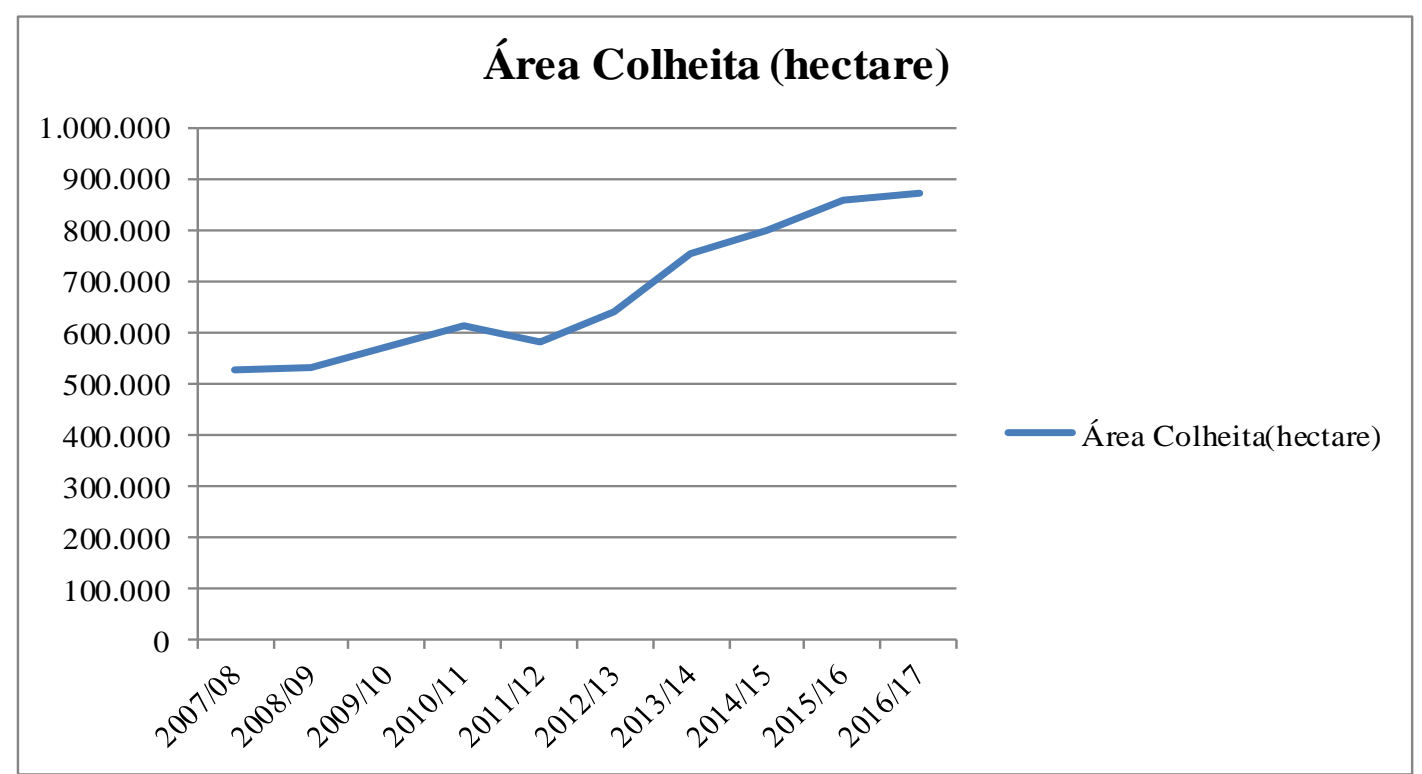

Fonte: Elaborado pelo autor (2018)

O Gráfico 4 representa de forma mais didática a eficiência da produção da cultura da soja em um hectare, dados em sacas/ha, modo utilizado na comercialização do commodities. Nota-se que de uma forma geral a produção em sacas $(60 \mathrm{~kg})$ cresceu ao decorrer dos anos, isso deve, principalmente, as variedades criadas em laboratório, bem como a inserção da tecnologia no campo que permite novas práticas benéficas à lavoura e à cultura.

Gráfico 4: Quantidade de sacas de sojas em um hectare no estado de São Paulo.

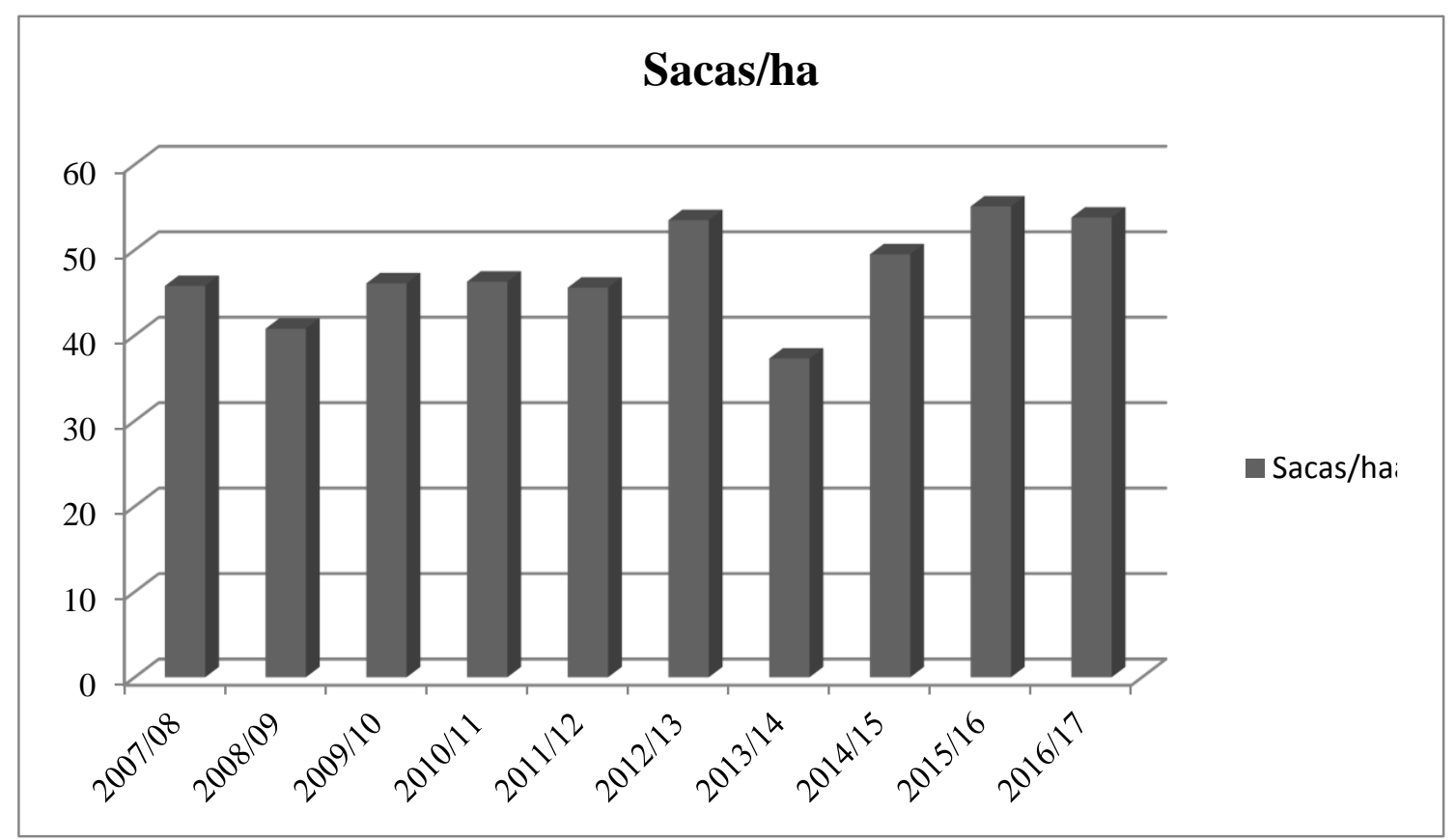

Fonte: Elaborado pelo autor (2018) 
Contudo, observa-se ainda, quem em alguns anos houve exceções consideráveis em relação à produção, como no caso da safra de 2012/13, que teve um aumento significativo de $15,7 \%$ da safra

anterior, continuando acima da safra posterior que ficou $28,4 \%$ abaixo da mesma. Isso se deu, principalmente, a uma positiva lucratividade no cultivo de oleaginosas. Também houve um fomento considerável na disponibilidade de créditos agrícolas, portanto mesmo em um possível cenário de perdas, o preço de certa forma compensaria a aposta na produção de soja no Brasil, o que refletiu diretamente no estado de São Paulo.

No Gráfico 5 é explanado em números o valor bruto por hectare que o produtor paulista alcançou nos últimos anos, a rentabilidade por área se deu por meio da simples conta em que foram levados em consideração a quantidade de sacas produzidas por hectare em média no estado, bem como o preço da saca de $60 \mathrm{~kg}$ nos referidos anos, ou seja, quanto de rendimento o produtor alcançou por hectare, como por exemplo no primeira safra do levantamento, 2007/08, onde o lucro foi de $1.400 \$$ por hectare, não levando em conta nesse caso os custos da produção.

Gráfico 5: Valor em reais (\$) da quantidade de sacas comercializadas por hectare no estado de São Paulo.

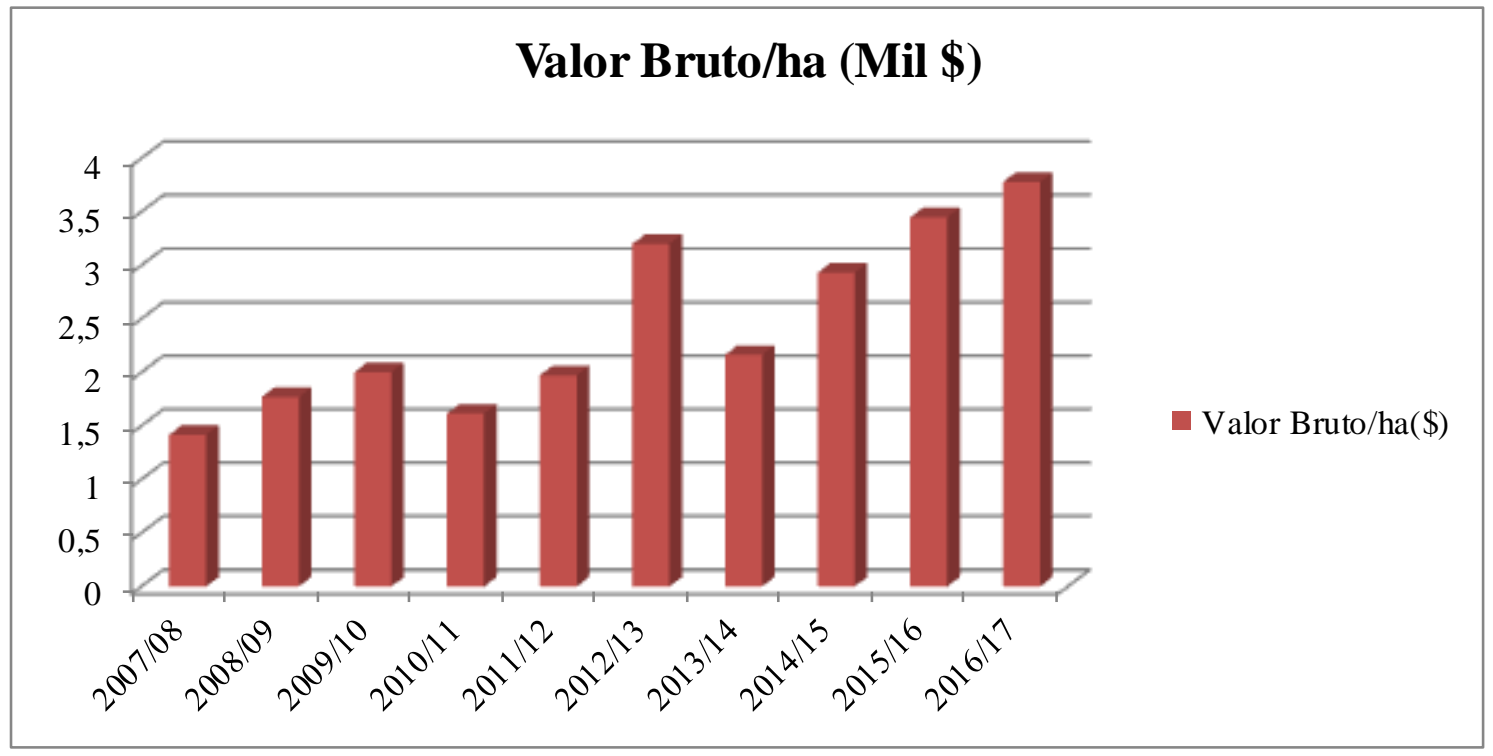

Fonte: Elaborado pelo autor (2018)

Em similaridade com o Gráfico 4, percebe-se no Gráfico 5 que a variação é crescente conforme o passar dos anos, porém nesse ponto a divergência em sua exceção, se dá não só na safra de 2012/13 muito pela ligação obvia entre produção e rentabilidade, mas também na safra 2010/11 que teve um dos piores resultados. Se comparada a safra 2008/09 a safra 2010/11 ficou 11,8\% abaixo, já em comparação a safra anterior (2009/10) a queda foi ainda maior, cerca de 21\%, mantendo-se na safra seguinte (2011/12) que obteve aumento de 16,7\% em relação a safra 2010/11, o que corrobora com a afirmativa por parte de produtores e especialistas como uma das piores safras das últimas décadas.

Pressupõe-se que este fato ocorreu em particular, pelas especulações acerca da economia americana que derrubou os preços do commodity no mercado futuro. Outro ponto primordial para esses resultados foi à produção norte-americana ter fugido do padrão devido a fortes chuvas, o que derrubou os preços no mercado internacional, pois os produtores tiveram que comercializar o produto de imediato, não havendo condições de estocagem (NOTÍ́CIAS AGRÍCOLAS, 2009). 


\section{CONCLUSÃO}

Apesar das constantes variações apresentadas, tanto na tabela quanto nos gráficos, notou-se que houve um crescimento considerável nos últimos anos em todos os fatores que foram analisados, principalmente na cotação da saca de soja que variou positivamente em 118,25\% nos últimos 10 anos, demonstrando uma valorização média de $11,82 \%$ ao ano.

\section{REFERÊNCIAS}

ABIOVE. Associação Brasileira das Indústrias de Óleos Vegetais. Coordenadoria de economia e estatística. ABIOVE, 2011. Disponível em: <

http://www.abiove.org.br/site/index.php?page=estatistica\&area=NCOyLTE=>. Acesso em: 22 out. 2018.

ABIOVE. Associação Brasileira das Indústrias de Óleos Vegetais. Coordenadoria de economia e estatística. ABIOVE, 2017. Disponível em:<

www.abiove.org.br/site/busca.php?tag=\&pag=38>. Acesso em: 22 out. 2018.

BRAUN, E.; TALAMINI, E. Estratégias de comercialização da soja: Uma análise das opções utilizadas pelos produtores rurais da região do alto Jacuí/RS. In: CONGRESSO SOCIEDADE BRASILEIRA DE ECONOMIA, ADMINISTRAÇÃO E SOCIOLOGIA RURAL, 48., 2010, Campo Grande. Anais..., 2010. p. 1-18. Disponível em: < http://www.sober.org.br/palestra/15/589.pdf>. Acesso em: 25 out. 2018.

CONAB. Companhia Nacional de Abastecimento. Acompanhamento da safra brasileira de grãos. Safra 2016/2017, $11^{\circ}$ Levantamento, setembro. Brasília: Conab, 2017.

CONAB. Companhia Nacional de Abastecimento. Acompanhamento da safra brasileira de grãos. Safra 2017/2018, $11^{\circ}$ Levantamento, setembro. Brasília: Conab, 2018.

COSTA NETO, P. R.; ROSSI, L. F. S. Produção de biocombustível alternativo ao óleo diesel através da transesterificação de óleo de soja usado em fritura. Química Nova, v. 23, n. 4, p. 531-537, 2000.

Disponível em: 〈http://www.scielo.br/pdf/qn/v23n4/2654.pdf>. Acesso em: 25 ago. 2018.

EMBRAPA. Empresa Brasileira de Pesquisa Agropecuária. Soja em números safra (2017/2018).

EMBRAPA, 2017. Disponível em: https://www.embrapa.br/soja/cultivos/soja1/dados-economicos.

Acesso em: 23 ago. 2018.

GUANZIROLI, C.E. Agronegócio no Brasil: perspectivas e limitações. In: Economia. Texto para Discussão 186. Universidade Federal Fluminense/ UFF. Abril/2006. Niterói/RJ. 59 p.

IMEA. Instituto Mato-grossense de Economia Agropecuária. Entendendo o mercado da soja. IMEA, 2015. Disponível em:

http://www.imea.com.br/upload/pdf/arquivos/2015_06_13_Paper_jornalistas_boletins_Soja_Versao_Final AO.pdf. Acesso em: 28 out. 2018.

KIIHL, R.A.S.; GARCIA, A. The use of the long-juvenile trait in breeding soybean cultivars. World Soybean Reserach Conference, 4., p. 994-1000, 1989.

MUNDSTOCK, C. M.; THOMAS, A. L. Soja: fatores que afetam o crescimento e o rendimento de grãos. Porto Alegre: Departamento de plantas de lavouras da Universidade Federal do Rio Grande do Sul: Evangraf, 2005.

NOTÍCIAS AGRÍCOLAS. Soja comercializada para 2010 tem pior preço do ano. Publicado em: 29 de outubro de 2009. Notícias Agrícolas. Disponível em:

https://www.noticiasagricolas.com.br/noticias/soja/56783-soja-comercializada-para-2010-tem-pior-precodo-ano.html\#.W-TdqdVKjIU. Acesso em: 12 out. 2018.

Nucleus,v.16,n.2,out.2019 